\title{
NEWS
}

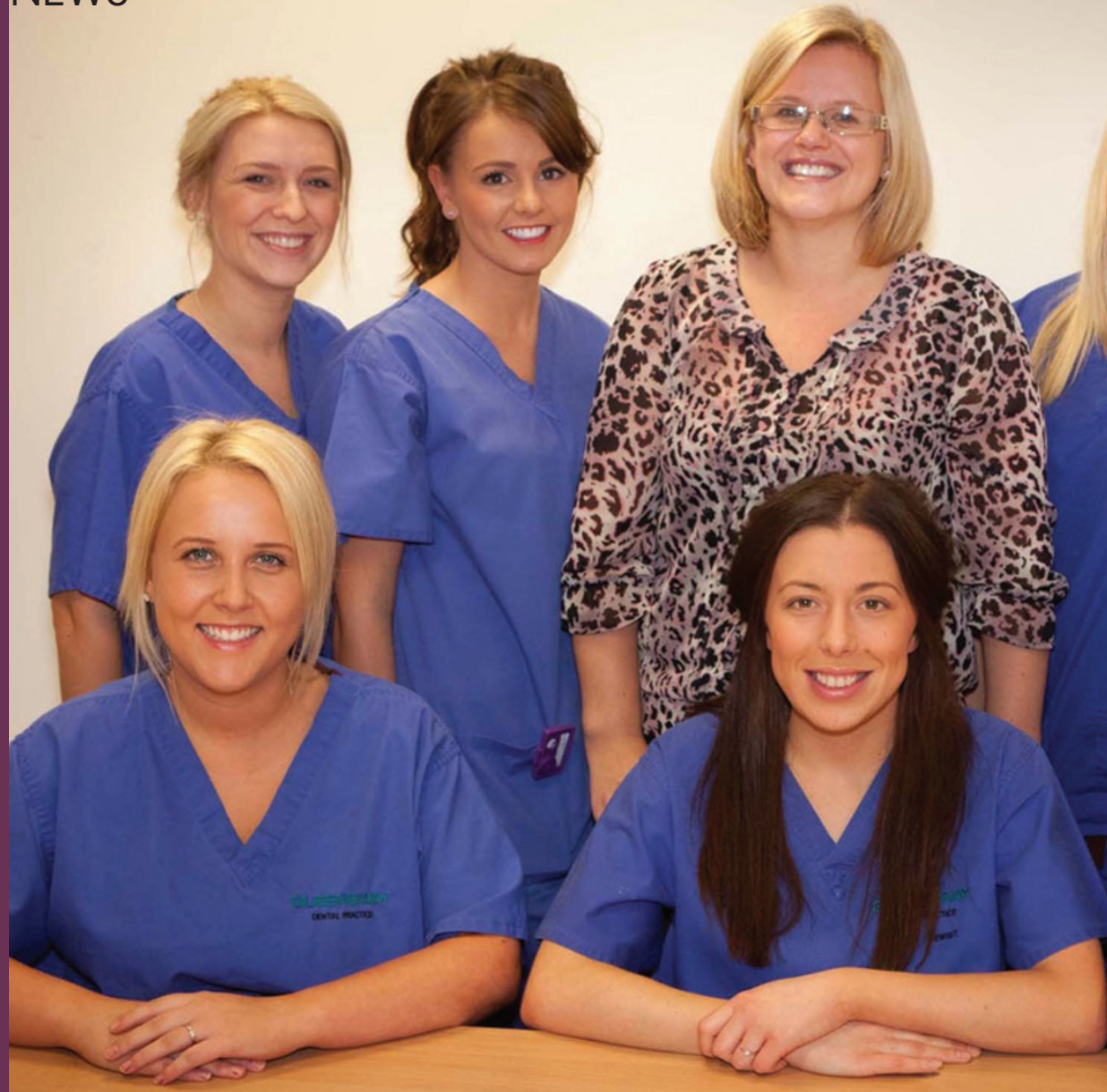

\section{SEVEN DENTAL NURSES EXPAND THEIR EXPERTISE}

Seven dental nurses celebrated the New Year in style having passed their Dental Sedation Nursing and Oral Health Certificates at Queensway Dental Clinic's Education Centre in Billingham, following a 20-week course.

Dental nurse Jade Hand said: 'The course has been brilliant and will benefit me in a number of ways. Queensway has recently opened a purpose built oral health room and now that I am qualified I can run sessions to educate patients about good oral health.'

Dental nurses from clinics across the region as well as Queensway were among those who passed the series of practical and theory tests involved and presented a completed portfolio.

Queensway Dental Clinic's on-site Education Centre delivers courses for both dentists and dental nurses throughout the year.

\section{TOBACCO GOES UNDER THE COUNTER IN WALES}

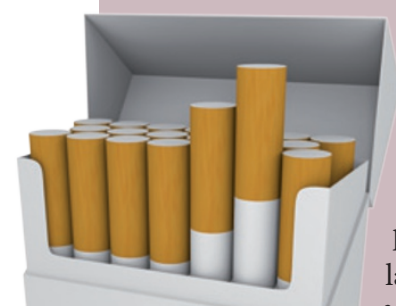

Big shops and supermarkets in Wales are now banned from displaying tobacco products under a new law which came into force in England earlier this year. The ban in Wales was announced just as international news reported that branding is to be removed from tobacco products altogether in Australia, and replaced with graphic images and health warnings.
In England and Wales, businesses

breaking the law on tobacco displays could be fined up to $£ 5,000$ or jailed for up to two years. Unbranded price lists will be displayed at tills and illustrated lists will be available upon request and demonstration of ID. The ban will include smaller shops and specialist tobacconists in April 2015.

Australia is the first country to remove branding from all tobacco products and the UK Government has been consulting over whether to follow suit in attempts to further reduce the number of people who smoke and take up smoking. The British Dental Health Foundation has lobbied for plain packaging for a number of years and welcomed the news of Australia 'setting a precedent'.

\section{MORE SUGAR IN UK CEREALS}

According to reports in the national press, cereals in the United Kingdom have up to $30 \%$ more sugar than their equivalent versions in the USA.

A survey conducted by the Sunday Times found that Kellogg's Special K has 17g of sugar per 100g in the UK compared to $13 \mathrm{~g}$ per 100g in the US. Nestlé Cheerios has $21.5 \mathrm{~g}$ of sugar per $100 \mathrm{~g}$ compared with just $4 \mathrm{~g}$ in the US. Alpen muesli contains 15\% more sugar in the UK than the US, according to the survey.

Kellogg's said that it altered recipes from country to country to cater for different palates adding: 'when you look at the amounts you are talking about it's still low when you consider what people eat across the day'.
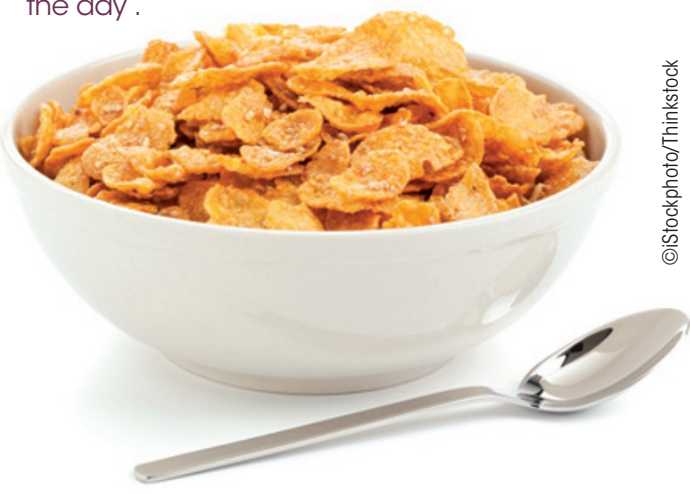

volume 10 spring 2013 